\title{
A Methodology for Assessment of Building Assembly Air Leakage Moisture Response, Condensation Risk, and Expected Durability When Subjected to Projected Future Climate Loads
}

\author{
David G. Kayll ${ }^{1}$, Maurice Defo ${ }^{2}$, Travis V. Moore ${ }^{3}$ and Michael A. Lacasse ${ }^{4}$ \\ ${ }^{1}$ Morrison Hershfield Limited, Building Specialty Services, \\ 2932 Baseline Rd., Ottawa, ON, Canada, dkayll@morrisonhershfield.com \\ ${ }^{2}$ National Research Council, Construction Research Centre, \\ 1200 Montreal Rd., Ottawa, ON, Canada, Maurice.Defoe@nrc-cnrc.gc.ca \\ ${ }^{3}$ National Research Council, Construction Research Centre, \\ 1200 Montreal Rd., Ottawa, ON, Canada, Travis.Moore@nrc-cnrc.gc.ca \\ ${ }^{4}$ National Research Council, Construction Research Centre, \\ 1200 Montreal Rd., Ottawa, ON, Canada, Michael.Lacasse@nrc-cnrc.gc.ca
}

Keywords: Climate Change, Durability, Air Barrier, Moisture Response, Condensation.

\section{Introduction}

In the 1980's and early 1990's, extensive analysis on air barrier system performance was conducted (Lux and Brown, 1989, Ojanen and Kumaran, 1995, Di Lenardo et al., 1996) such that rational reference points for wall assembly design could be developed under historical Canadian climate patterns. The underlying intent was aligned with the fundamental needs to a) reduce energy use, and b) control condensation within moisture sensitive materials of a wall assembly.

This research work led to the development of the CAN/ULC S741 Standard for Air Barrier Materials - Specification and CAN/S742 Standard for Air Barrier Assemblies - Specification. Within these standards, performance criteria was established for the performance rating of air barrier materials and performance classification of air barrier assemblies based upon maximum allowable air leakage rates. The final component of this work was intended to be the development of a design approach that would integrate air barrier assembly performance with a building's design needs. Unfortunately, funding for the completion of this research and integration into building codes was halted before this work could be completed and published.

In the preparation of the 1995 National Building Code of Canada, under Part 5 Environmental Separation, there was a desire to define performance criteria for air barrier materials and air barrier assemblies. Since the research was not yet completed on air barrier assembly requirements, the ability to educate the design community on meeting minimum criteria was not yet possible. Hygrothermal computer modelling was still in its infancy and required significant assumptions on material performance to predict water vapour and moisture movement through assemblies, let alone the physics of air movement and condensation deposition. It was therefore accepted that codification of air barrier assembly performance was not reasonably practical.

By 2011 the Canadian Commission on Building and Fire Codes determined that it was 
appropriate to consider air barrier assembly performance criteria in the National Building Code of Canada. The Standing Committee on Environmental Separation was tasked to:

"Develop quantifiable/explicit air leakage requirements for assemblies ...and investigate the feasibility of creating a design approach to air leakage that would mimic the risk-based approach used for structural design where assemblies are designed to resist specified loads." (CCBFC 2011)

Parallel with this activity was the initiative to update CSA S478 Guideline for Durability of Buildings, with an emphasis on how appropriate building envelope design could be accomplished using the breakthroughs and improvements in computational hygrothermal modelling and analysis that had occurred in the intervening 20 years.

\section{The Problem}

In the development of the necessary changes to the National Building Code of Canada to adopt and implement a rational air barrier assembly design approach, it was identified that an exterior wall assembly durability risk assessment must assess whether various agents of deterioration will result in the;

\section{Shortening of the expected predicted service life of associated structural components, with resulting structural damage or risks of collapse, and/or}

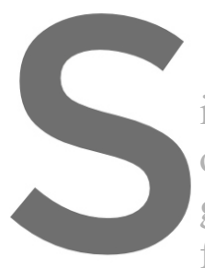

\section{Promotion of 1}

Air leakage through if resulting condensation of organic component growth. In order to assess following analysis methodology was develope
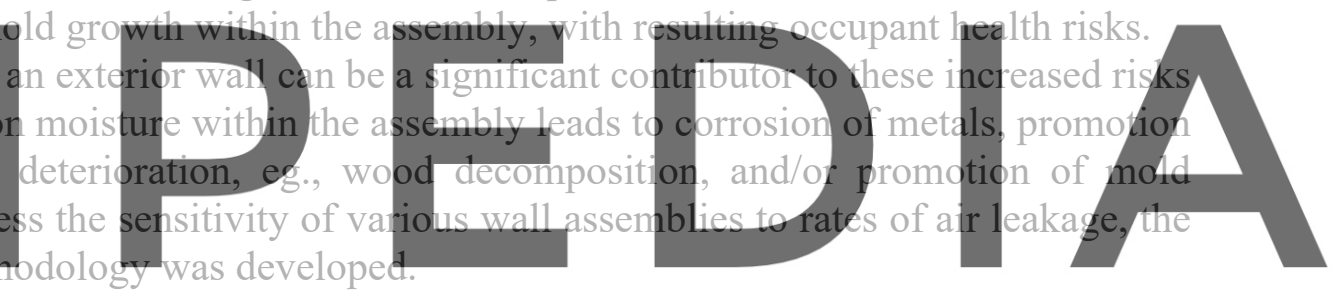

Register for freelasistipsthwowasgojpedia.com to download the version without the watermark

An analysis methodology was developed as described below. This paper focuses this analysis on one set of the variables to allow for assessment of the validity of the methodology.

Air leakage and its impact on wall assembly durability related to condensation and mold growth is a relative function of the following criteria:

1. Building occupancy characteristics - the internal hygrothermal loads imposed on the wall assembly. Different occupancy types affect interior hygrothermal loads. For the preliminary analysis in this paper, a residential occupancy was selected.

2. Building height - Building height directly influences wind loads and, therefore, air leakage rates (Shaw and Tamura, 1977). For this preliminary analysis, a single building height group was selected; a "low rise", 31/2 storey residential property ( $<10 \mathrm{~m}$ tall).

3. Wall assembly composition - In this methodology, wall assemblies are assessed by the level of moisture tolerance of specific materials, the ability of the assembly to redistribute moisture within the assembly, and the ability of the assembly to dissipate moisture before it can cause deterioration or mold growth. For this preliminary analysis, a single wall assembly type was selected; a wood-framed wall with brick cladding reference wall, W1, as described in Section 3.1. Being of wood-frame construction, with the exterior masonry 
cladding structurally attached to the wood studs, this assembly configuration is considered at relatively higher risk of potential negative impacts from moisture.

4. Building location climate characteristics - the historic and predicted future climate characteristics taken from a selected location in Canada. For the purposes of this initial analysis, the historic and future climate loads for the city of Winnipeg, Manitoba were selected as a baseline; Climate Zone 7A, 5670 HDD (NBC 2015). See Section 3.3.

5. Wall assembly air leakage rate - Variations in air barrier assembly air leakage rate were used to assess durability response. For the purposes of this initial analysis, air exfiltration due to imperfections in the air barrier system was calculated assuming air leakage rates of $0.05,0.15$ and $1.0 \mathrm{~L} /\left(\mathrm{s} \cdot \mathrm{m}^{2}\right) @ 75 \mathrm{~Pa}$. The first two represent air barrier assembly classifications A1 and A3 (CAN/ULC S472, 2011), while the final value was used to provide a quality check on the modelled results. An air leakage rate of 0.0 was also modelled to give a baseline for comparison of results and the ability to assess the impact of wind-driven rain without air leakage. The air leakage path is described in Section 3.2.

\subsection{Reference Wall (W1)}

Figure 1 shows the configuration of reference wall (W1). This wall assembly was chosen as an initial reference since a similar wall assembly was analyzed during the development work of the early 1990's (Ojanen and Kumaran, 1995, Di Lenardo et al., 1996). This provided an initial comparison of this new methodology to the approach taken previously. The reference wall W1

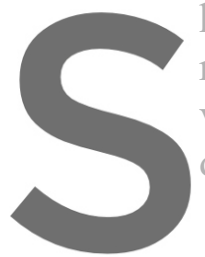
has an effective RSI of requirements for a low ventilation $(\mathrm{NBC}, 2015)$ decisions. This approach was


Register for free at https//www.scipedia.com to download the version without the watermark

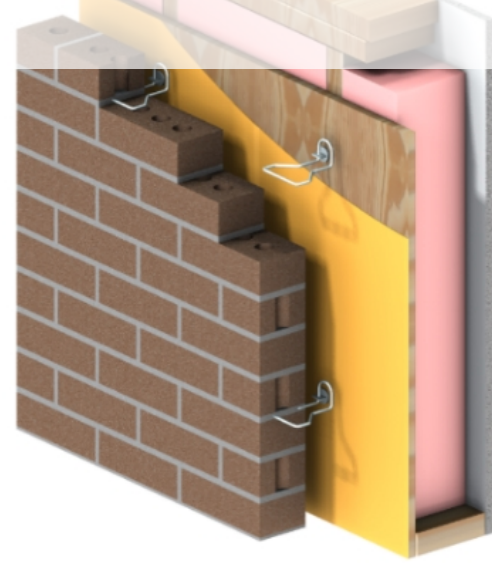

Figure 1. Reference wall (W1) schematic.



Figure 2. Modelled path of air movement.

The reference wall $\mathrm{W} 1$ comprises, from exterior to interior:

- Brick masonry $(90 \mathrm{~mm})$ 
- Drainage cavity $(25 \mathrm{~mm})$

- Exterior sheathing membrane (30-min building paper, $0.22 \mathrm{~mm}$ )

- Exterior oriented strand board sheathing $(11 \mathrm{~mm})$

- Wood stud (spruce, $140 \mathrm{~mm}$ )

- Cavity insulation (glass fibre batt, $140 \mathrm{~mm}$ )

- Vapour barrier (6-mil polyethylene, $0.15 \mathrm{~mm}$ )

- Gypsum wallboard, primed and painted $(12.7 \mathrm{~mm})$

\subsection{Air Flow Path}

To implement the air flow calculations, it was assumed that the air exfiltration occurs through an orifice in the air barrier system. The area of the orifice was estimated using the equation for sharp-edged orifice (ASHRAE, 2017). The orifice area was computed for each air leakage rate, assuming a rectangular orifice shape with a width of $0.05 \mathrm{~m}$, the thickness of the opening was computed for each air leakage rate.

The risk of moisture condensation increases when the exfiltration path is longer, i.e., when air enters the insulation cavity at the bottom right corner and exits at the top right corner or visversa (Ojanen and Kumaran 1995). For this paper, it was assumed that air penetrates the cavity through a crack between the interior drywall and the flooring via imperfect contact between the bottom plate and the vapour barrier and exits through an opening between the top plate and the OSB sheathing, as shown in Figure 2.
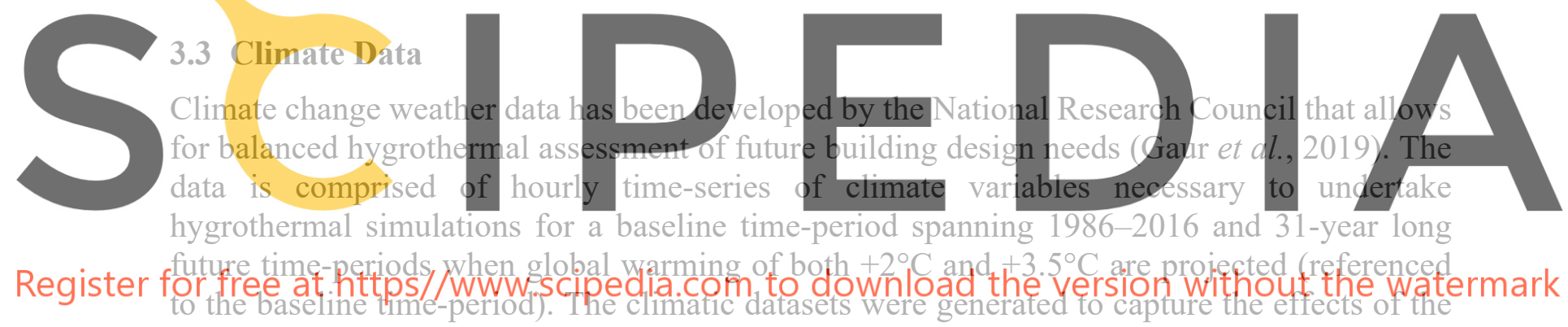

internal variability of the climate on future climate projections in fifteen hourly realizations that are part of the datasets derived from the large ensemble of climates simulated by the Canadian Regional Climate Model, version 4 (CanRCM4), each initialized under a different set of initial conditions in the CanESM2 global climate model. The generated datasets do not capture the uncertainty in climatic projections that may arise from the use of other global and regional climate models in simulating the regional climate and future climate projections.

For this study, only the 31-year time-periods corresponding to global warming of $+3.5^{\circ} \mathrm{C}$ were considered; 1986-2016 Historical ("H"), and 2062-2092 Future ("F"). Each timeline comprises 15 realizations or runs. Since it can be onerous to consider all runs, it was decided that, for this preliminary study, only the median run (based on moisture index, MI) was selected from each timeline. The moisture index (Cornick and Dalgliesh, 2003) of a run was calculated as the average of the 31 yearly MI of that run.

For hygrothermal simulations in this study, two representative years were selected from the median run of the Historical and Future climate data. Since the purpose of the simulation is to address condensation risk, the first and second years were; 1) the year with the average annual temperature, and 2) that with the lowest annual temperature, of the 31-year data of the run. They 
correspond respectively to the years 2008 and 2003 for Historical data, and 2092 and 2063 for Future data. Figure 3 compares the temperature, rain, relative humidity and wind speed profiles for the city of Winnipeg in the two years selected. The trend observed for the whole run is also present in the two-year data. It can be observed that; average temperature increases between the two timelines, while the wind speed decreases marginally. Rain and RH do not vary in average between the two timelines but more extreme annual RH values will be present in the future.
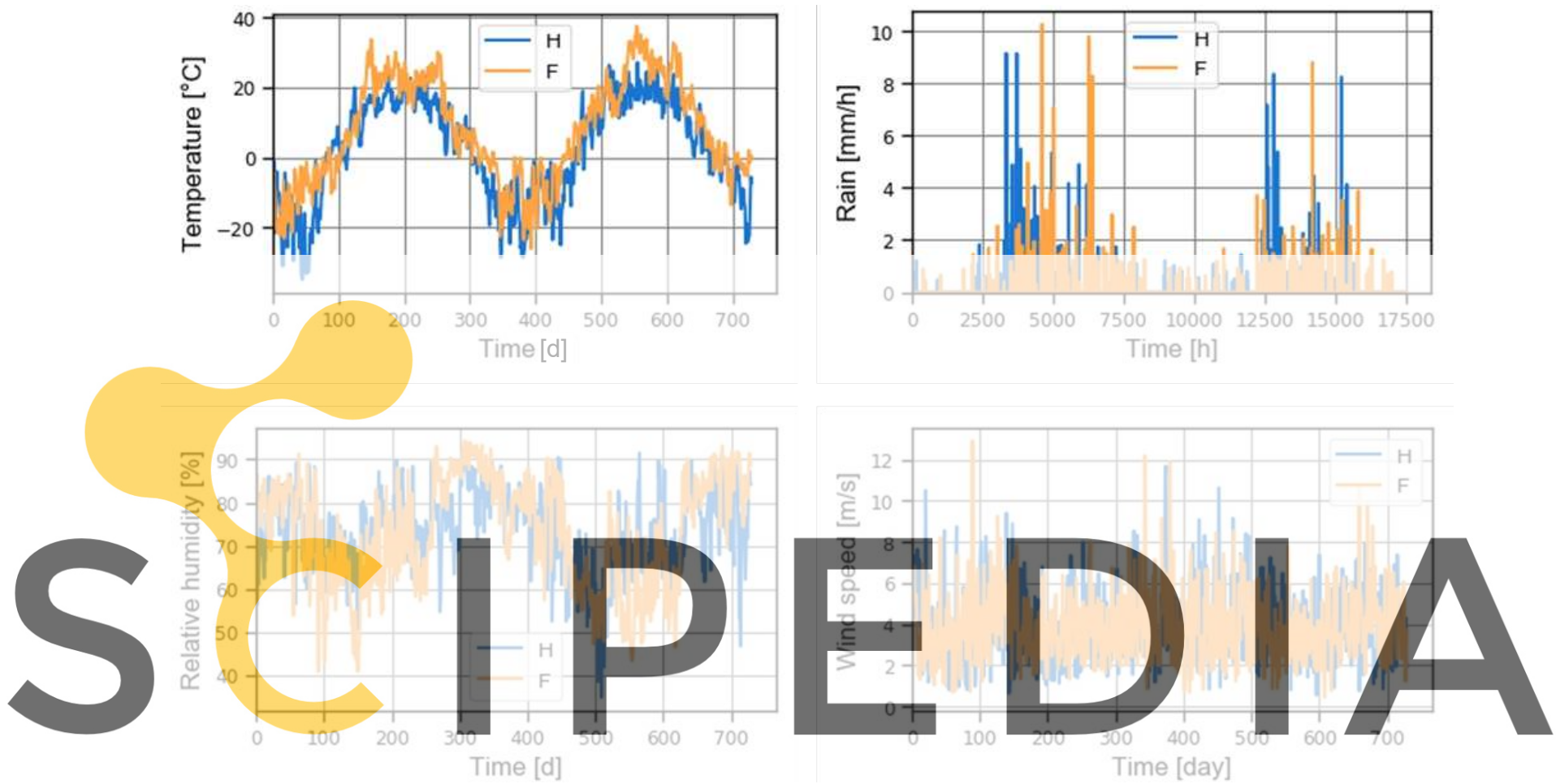

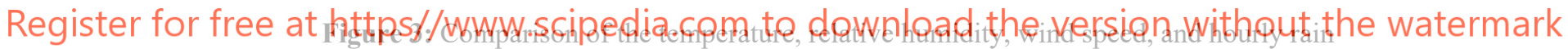

distributions for the two years of historical and future climate data selected for

hygrothermal simulations. Day 0 or hour 0 corresponds to January 1 st of the first year.

\subsection{Hygrothermal Model Used}

DELPHIN 5, v5.9.4, was used for hygrothermal simulations. Important features of DELPHIN are its ability to handle wind-driven rain deposition and shortwave/longwave radiation as part of boundary conditions, as well as air leakage, moisture, and heat sources. A 2D configuration of the wall consisting of the vertical section passing through the insulation cavity was considered. This excludes the wood studs.

\subsection{Boundary Conditions}

Hourly data of climate loads (temperature, $\mathrm{RH}$, wind velocity, wind-driven rain, shortwave and longwave radiations) on the cladding exterior surface were prepared according to DELPHIN specifications. Wind-driven rain was calculated using the ASHRAE (2016) standard method. Outdoor and indoor pressures were derived from differential pressure. The indoor T and RH were computed assuming that the building is equipped with heating and air conditioning with a 
dehumidifier. Using ASHRAE (2016) formula, the indoor T varied from $21^{\circ} \mathrm{C}$ to $24^{\circ} \mathrm{C}$ and the indoor RH varied from $46 \%$ to $50 \%$. For initial conditions, the $\mathrm{T}$ and $\mathrm{RH}$ of all layers were set to $21^{\circ} \mathrm{C}$ and $50 \% \mathrm{RH}$. As well the initial pressure was set to $101.3 \mathrm{kPa}$. Other parameters used for boundary conditions are summarized in Table 1. All material properties were obtained from the NRC material property database (Kumaran et al., 2002).

Table 1. Boundary Conditions.

\begin{tabular}{|c|c|c|}
\hline \multicolumn{1}{|c|}{ Boundary Conditions } & Outdoor & Indoor \\
\hline Heat transfer & & $8^{* *}$ \\
\hline Convective heat transfer coefficient, $\alpha\left(\mathrm{W} / \mathrm{m}^{2} \mathrm{~K}\right)$ & $5.82+3.96 V^{*}$ & - \\
\hline Shortwave absorption coefficient & 0.6 & - \\
\hline Cladding longwave emission coefficient & 0.9 & - \\
\hline Ground longwave emission coefficient & 0.9 & - \\
\hline Ground albedo & 0.1 & $5.9 \times 10^{-8}$ \\
\hline Moisture transfer & $\alpha \times 7 \times 10^{-9}$ & \\
\hline Water vapour transfer coefficient $\beta(\mathrm{s} / \mathrm{m})$ & & 2 \\
\hline Air leakage & 2 & \\
\hline
\end{tabular}

*: $\mathrm{V}$ is the wind velocity $(\mathrm{m} / \mathrm{s})$

**: Indoor heat transfer coefficient encompasses both the convective and the radiative components

\section{Results}

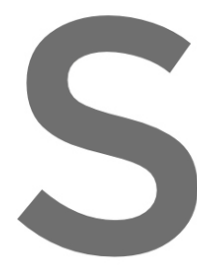

\section{The results of the preliminary in the overall evaluation Residential occup Higher risk wall assemb Historical and Future weather data

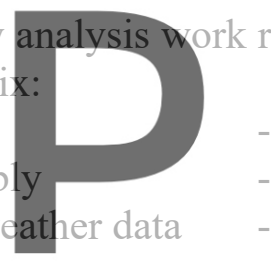

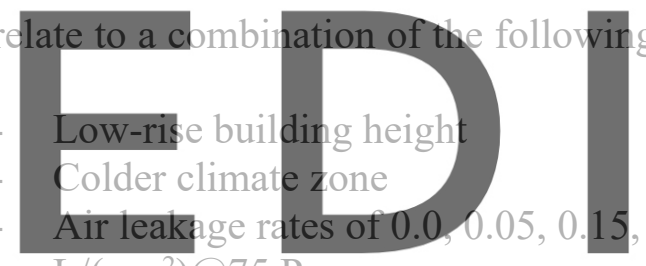

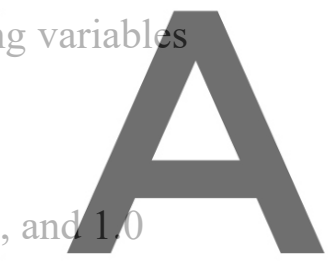
$\mathrm{L} /\left(\mathrm{S} \cdot \mathrm{m}^{2}\right) @ 75 \mathrm{~Pa}$

Register for The initiah tear was considered a conditioning vear to tallow stabilization after the initial boundary set points. Results are presented for relative humidity only, as the conditions for mold development were not reached over the two year simulation. Only results for the second year are discussed.

Preliminary results show that, based on the air path used, either; a) the bottom portion of the OSB in contact with the insulation, or b) the top left surface of the bottom plate, are more susceptible to condensation. For this paper, the results for the top left surface of the bottom plate was used to compare the impact of air leakage rates and climate change.

\subsection{Effects of Air Leakage Rate and Climate Change}

Figure 4 and 5 show the relative humidity profiles for each air leakage rate for the top left surface of the bottom plate for the reference wall (W1), for Historical (Figure 4) and Future (Figure 5) climate scenarios. Some key observations can be made: 

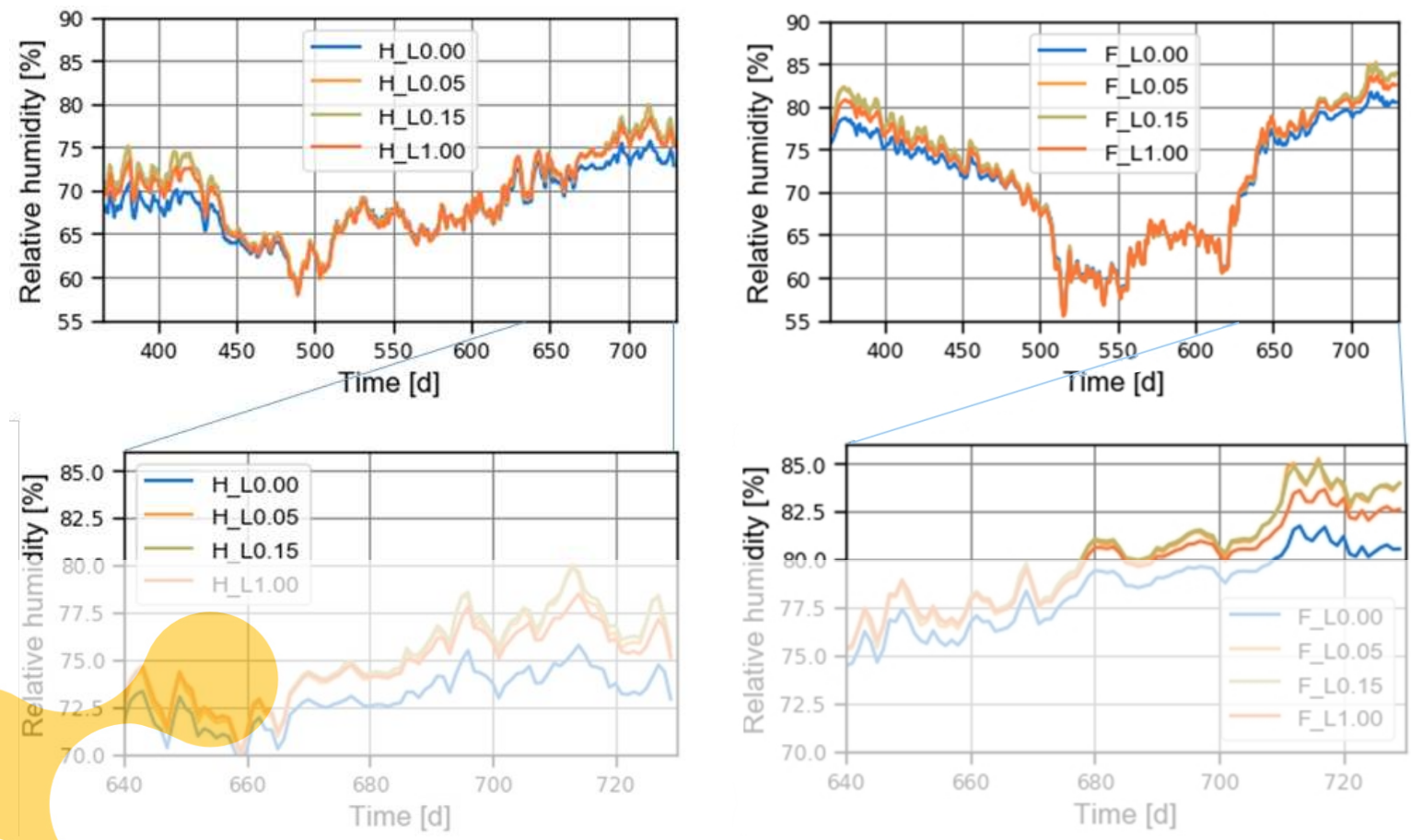

Figure 4. RH profiles, top left surface of bottom
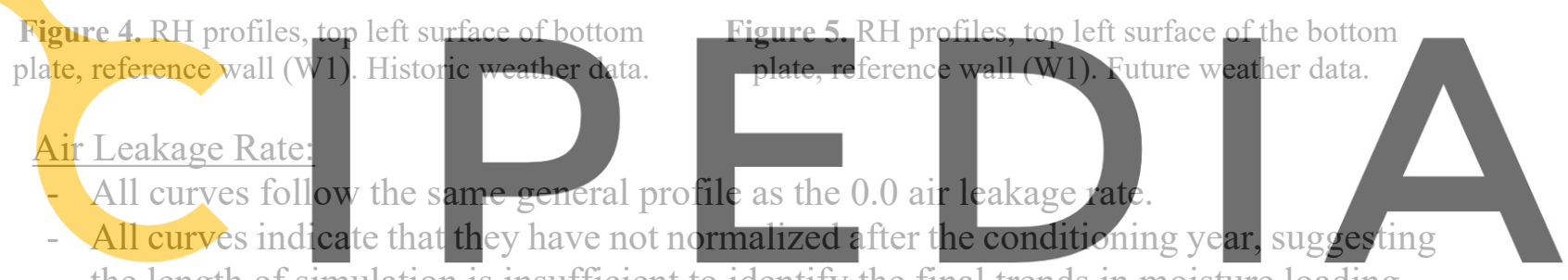
the length of simulation is insufficient to identify the final trends in moisture loading.

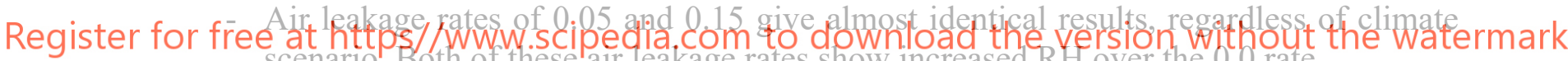
scenario. Both of these air leakage rates show increased RH over the 0.0 rate.

Air leakage rate of 1.0 has lower RH compared to 0.05 and 0.15 . This is due to the cavity warming from the higher rate of warm air leakage (Ojanen and Kumaran 1995)

Climate Change:

- Differences of up to 4\% for Historical climate and 5\% for Future climate are found between the case with no air leakage and the cases with leakage rates of 0.05 and 0.15 .

- The Future climate model shows that up to $85 \% \mathrm{RH}$ is reached in wood materials, while in the Historical climate model, up to $80 \%$ is reached.

- Future climate data shows an increase of up to $8 \%$ in RH over Historical climate.

- Future climate shows sustained increase in RH versus Historical climate after the 710 day mark in the simulation. Historical climate shows a decrease in RH while Future climate shows sustained increase.

- The RH has not normalized for both climate scenarios, suggesting that the length of simulation is insufficient to provide suitable information on moisture loading. 


\section{Conclusions}

This preliminary work is intended to document a methodology for assessment of air leakage rate and climate change on wall assembly durability. The initial assessment demonstrates that results that indicate the relative wall assembly performance under different air leakage rates can be used to establish inputs into a durability analysis. The results also demonstrate that differences between historical and future climate data suggests the methodology has merit.

However, it was also determined that conducting hygrothermal simulation using two years of climate data does not provide sufficient output data to assess stabilized moisture trends and mold development risks. Since mold development risk is a key criteria for long term durability assessment, future analysis work must use longer simulation durations.

Also critical is the length of the simulation "conditioning" time frame to allow the assembly component normalization of temperature and moisture conditions. Longer simulation timeframes will provide a better understanding of required conditioning durations.

Future work must analyze different; climate zones, building heights, building occupancies, wall assembly composition, and formal durability risk assessments for each result to understand the importance of air barrier performance on durability in a changing climate.

\section{ORCID}

David Kayll: https://orcid.org/0000-0002-3854-9408

Maurice Defo: https://orcid.org/0000-0001-9212-6599

Travis Moore: https://orcid.org/0000-0002-4920-9193

Michael Lacasse: https://orc

References

ANSI/ASHRAE. (2016).

Buildings. Atlanta: ASHR AE


ASHRAE Handbook - Fundamentals (2017). ASHRAE, Atlanta

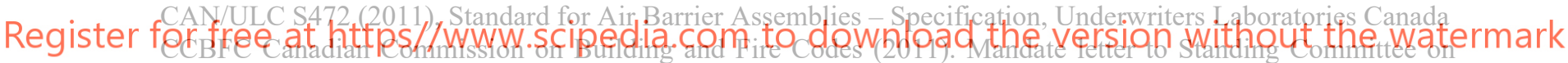

Environmental Separation.

Cornick, S.M. and Dalgliesh, W.A. (2003). A Moisture index to characterize climates for building envelope design. National Research Council Canada 45658

Di Lenardo, B., Brown, W.C., Dalgleish, W.A., Kumaran, M.K. and Poirier, G.F. (1996) CCMC Technical Guide for Air Barrier Systems for Exterior Walls of Low-Rise Buildings Masterformat Section: 07272,

Gaur, A., Lacasse, M. and Armstrong, M. (2019). Climate data to undertake hygrothermal and whole building simulations under projected climate change influences for 11 Canadian cities. Data, 4(2), 72. National Research Council Canada

Kumaran M.K., Lackey, J.C., Normandin, N. and Van Reenen, D. (2002) Summary Report From Task 3 of MEWS Project at the Institute for Research in Construction - Hygrothermal Properties of Several Building Materials. National Research Council Canada

Lux, M.E. and Brown, W.C. (1989). An air barrier for the building envelope. Proceedings of Building Science Insight '86. National Research Council of Canada, Ottawa. NRCC 29943.

National Building Code Canada 2015 (NBC), Codes Canada

Ojanen, T. and Kumaran, M.K. (1995). Effect of exfiltration on the hygrothermal behaviou of a residential wall assembly: Results from calculations and computer simulations. Symp. on Moisture Problems in Building Walls, (pp. 157-167). Porto, Portugal.

Shaw, C.Y. and Tamura, G.T. (1977). The Calculation of Air Infiltration Rates Caused by Wind and Stack Action for Tall Buildings. National Research Council Canada 761, ASHRAE Transactions, 83,2, pp 145-158. 